Artikel Review

\title{
Sarcopenia dan Risiko Jatuh pada Pasien Geriatri
}

\author{
Anggi Setiorini* \\ Departemen Anatomi, Histologi dan Patologi Anatomi, Fakultas Kedokteran, Universitas Lampung, Indonesia \\ *Corresponding author: anggisetiorini@ fk.unila.ac.id
}

\begin{abstract}
Background: In geriatric patients, there are major changes associated with human aging, namely a progressive decrease in muscle mass, which can result in a decrease in body strength and functionality. Sarcopenia can be a risk factor for falls in the elderly besides the factors of increasing age, drug use, cognitive impairment, and sensory deficits. Purposes: The aim is to know the features of sarcopenia and the risk of falling in geriatric patients. Method the literature search method through Pubmed and Google Scholar found 26 articles on sarcopenia and the risk offalling in geriatric patients. Results: Sarcopenia is a decrease in skeletal muscle mass associated with age followed by a decrease in muscle strength and/or function. Increasing age will reduce muscle mass and consequently can lead to increased risk of falls and sarcopenia. As many as one third of the elderly will experience a fall at least once a year. Conditions secondary to falls may actually increase the risk of injury from falls (eg, hip fractures and head injuries). One of the most effective ways to reduce the incidence of falls is to practice a healthy lifestyle, avoid stress, and do physical exercise. Conclusion: Sarcopenia, which is exacerbated by a decrease in physical activity, can cause a decrease in overall organ function which can lead to falls in the elderly.
\end{abstract}

Keywords: geriatric patients, risk of falling, sarcopenia

\begin{abstract}
ABSTRAK
Latar Belakang: pada pasien geriatri terjadi perubahan besar yang terkait dengan penuaan manusia yaitu penurunan massa otot secara progresif, yang dapat mengakibatkan terjadinya penurunan kekuatan dan fungsionalitas tubuh. Sarcopenia dapat menjadi salah satu faktor risiko jatuh pada lansia disamping faktor bertambahnya usia, penggunaan obat, gangguan kognitif dan defisit sensorik. Tujuan mengetahui gambaran sarcopenia dan risiko jatuh pada pasien geriatri. Metode pencarian literature melalui Pubmed dan Google Scholar didapatkan 26 artikel mengenai sarcopenia dan risiko jatuh pada pasien geriatri. Hasil: Sarkopenia merupakan penurunan massa otot rangka yang terkait dengan usia yang diikuti dengan adanya penurunan kekuatan dan/atau fungsi otot. Usia semakin lanjut akan menurunkan massa otot akibatnya bisa menyebabkan meningkatkan risiko jatuh dan sarcopenia. Sebanyak sepertiga dari lansia akan mengalami kejadian jatuh setidaknya sekali selama setahun. Kondisi sekunder dari kejadian jatuh dapat meningkatkan risiko dari cedera akibat jatuh (misalnya, patah tulang pinggul dan cedera kepala). Salah satu cara yang cukup efektif untuk menurunkan angka kejadian jatuh adalah dengan mempraktikkan gaya hidup sehat, menghindari stress, melakukan kegiatan latihan fisik. Simpulan: Sarcopenia yang diperparah dengan adanya penurunan aktivitas fisik, dapat menyebabkan penurunan fungsi organ tubuh secara keseluruhan yang dapat mengakibatkan terjadinya kejadian jatuh pada lansia.
\end{abstract}

Kata kunci: pasien geriatrik, risiko jatuh, sarcopenia 


\section{PENDAHULUAN}

Sarcopenia berasal dari bahasa Yunani yaitu Sarx untuk "daging" dan Penia untuk "kehilangan", mengacu pada terjadinya pengurangan massa otot dan fungsi dengan penuaan (1). Sarkopenia secara signifikan terkait dengan cacat fisik yang terjadi pada pria dan wanita, terlepas dari etnis, usia, morbiditas, obesitas, pendapatan, atau perilaku kesehatan yang mereka terapkan (2).

Sarkopenia adalah suatu sindrom geriatrik yang baru dikenali, ditandai dengan penurunan otot rangka yang berkaitan dengan penambahan usia dan kekuatan otot atau kinerja fisik yang makin menurun (3). Studi sebelumnya telah mengkonfirmasi hubungan sarcopenia dan hasil kesehatan yang dapat merugikan, seperti jatuh, kecacatan, masuk rumah sakit, penempatan perawatan jangka panjang, kualitas hidup yang lebih buruk, dan kematian (4).

Insiden jatuh pada lanjut usia semakin meningkat. Jatuh adalah penyebab cedera paling umum yang terjadi pada orang lanjut usia. Pada individu yang rapuh dan polimorbid, jatuh paling sering disebabkan oleh etiologi multifaktorial; kelemahan terkait usia, penyakit kronis yang bertepatan dan interaksi dengan lingkungan luar. Akibat paling serius dari jatuh termasuk patah tulang pinggul dan cedera intrakranial (5). American Geriatric Society merekomendasikan pemeriksaan jatuh pada setiap tahunnya dan pemeriksaan keseimbangan pada orang berusia 65 tahun. Intervensi multifaktorial harus ditargetkan terutama pada orang dengan dua atau lebih jatuh atau dengan riwayat cedera setelah jatuh (6).

Angka kejadian sarcopenia, dengan variasi regional dan usia sebesar $1-29 \%$ pada populasi yang tinggal di suatu komunitas, 14$33 \%$ pada populasi dengan perawatan jangka panjang dan $10 \%$ pada populasi dengan perawatan rumah sakit (7). Bukti kualitas menunjukkan bahwa adanya intervensi olahraga meningkatkan kekuatan otot dan kinerja fisik (8). Hasil dari intervensi nutrisi masih samar-samar karena jumlah studi yang sedikit dan desain studi yang heterogen (9).

Menggunakan aturan baku yang umum digunakan untuk menentukan sarcopenia, termasuk pengurangan massa otot dan gabungannya, pada populasi lansia Jepang, prevalensi sarcopenia berkisar antara 2,5 hingga $28,0 \%$ pada pria dan 2,3 hingga $11,7 \%$ pada wanita (10).

Prevalensi jatuh pada lansia dalam satu tahun terakhir adalah $28,1 \%$, dan biasanya terjadi di tempat tinggal mereka sendiri. Di antara lanjut usia yang jatuh, 51,5\% mengalami satu kali jatuh dan $12,1 \%$ dan mengalami patah tulang, biasanya di tungkai bawah (11).

Prevalensi jatuh lebih tinggi terjadi pada wanita, dewasa lanjut usia, dan pasien dengan penyakit seperti diabetes, penyakit jantung, dan artritis. Kejadian jatuh mencapai hampir sepertiga dari orang dewasa yang lebih tua, dan prevalensinya lebih tinggi pada segmen tertentu dari populasi yang bersangkutan. Sekitar $12 \%$ dari orang dewasa yang lebih tua mengalami patah tulang. Faktor-faktor yang terkait dengan kejadian jatuh pada usia lanjut yang diidentifikasi dalam penelitian ini dapat digunakan untuk membuat tindakan pencegahan (12).

Menurut data Bureau of the Cencus USA, dilaporkan bahwa Indonesia akan mengalami kenaikan jumlah lanjut usia sebesar 414\% pada tahun 1990-2025. Angka ini merupakan angka tertinggi di dunia dan menunjukkan bahwa angka harapan hidup di Indonesia meningkat pesat. Peningkatan angka harapan hidup lansia menimbulkan berbagai masalah polemik, seperti masalah sosial, psikologis, dan psikis akibat proses degeneratif pada lansia (13). 
Perkembangan penduduk lansia di Indonesia menarik untuk diamati, dimana cenderung terjadi peningkatan jumlah lansia dari tahun ke tahun. Kantor Kementerian Koordinator Kesejahteraan Rakyat (KESRA) melaporkan, jika tahun 1980 usia harapan hidup 52,2 tahun dan jumlah lansia 7.998.543 orang (5,45\%), maka pada tahun 2006 menjadi 19 juta orang $(8,90 \%)$ dan usia harapan hidup juga meningkat (66,2 tahun). Pada tahun 2010 perkiraan penduduk lansia di Indonesia akan mencapai 23,9 juta atau 9,77 $\%$ dan usia harapan hidup sekitar 67,4 tahun. Badan kesehatan dunia WHO menyatakan bahwa penduduk lansia di Indonesia pada tahun 2020 mendatang diperkirakan mencapai angka 28,8 juta orang atau tercatat $11,34 \%$, dengan usia harapan hidup 71,1 tahun (14).

Pencarian literatur dilakukan dengan menggunakan Sumber PubMed dan Google Scholar. Didapatkan 26 artikel dipilih untuk ditinjau, dilaporkan dalam sebuah narasi cara dalam bentuk tinjauan mendalam tentang topik yang dipilih. Didapatkan dari Pubmed 8 artikel mengenai risiko jatuh dan latihan untuk menangani jatuh serta 16 artikel mengenai sarcopenia dan muskuloskeltal pada pasien geriatri lalu dari google scholar didapatkan 2 artikel mengenai latihan bagi lansia serta jumlah lansia di Indonesia.

\section{TINJAUAN LITERATUR \\ Sarcopenia}

Sarkopenia merupakan penurunan massa otot rangka yang terkait dengan usia yang diikuti dengan adanya penurunan kekuatan dan/atau fungsi otot. Sarcopenia yang saat ini banyak dihadapi oleh tenaga medis dapat digunakan untuk mengetahui peningkatan frekuensi dalam praktik klinis dan penelitian dalam pengobatan geriatri, tetapi juga dalam berbagai pengobatan lainnya (15).
Tabel 1. Faktor yang memperparah Sarcopenia

\begin{tabular}{|c|c|}
\hline Aging & $\begin{array}{l}\text { Age Associated muscle } \\
\text { loss }\end{array}$ \\
\hline Disease & $\begin{array}{l}\text { Inflammation condition } \\
\text { (e.g., organ failure, } \\
\text { malignancy) } \\
\text { Osteoarthritis } \\
\text { Neurological disorders }\end{array}$ \\
\hline Inactivity & $\begin{array}{l}\text { Sedentary behaviour } \\
\text { (e.g., limited mobility or } \\
\text { bedrest) } \\
\text { Physical inactivity }\end{array}$ \\
\hline Malnutrition & $\begin{array}{l}\text { Under nutrition or } \\
\text { malabsorption } \\
\text { Medication related } \\
\text { anorexia } \\
\text { Over-nutrition/obesity }\end{array}$ \\
\hline
\end{tabular}

Sumber: Cruz, 2019.

Kekuatan otot pada geriatri menentukan salah satu penilaian dalam sarkopenia (2). Geriatri yang memiliki kekuatan otot yang baik memiliki kualitas hidup yang baik. Usia semakin lanjut akan menurunkan massa otot karena penuaan akibatnya bisa menyebabkan meningkatkan risiko jatuh dan sarkopenia. Status nutrisi pada populasi lansia berhubungan dengan kemampuan dan kekuatan fungsional (16).

Prevalensi sarcopenia bervariasi di seluruh dunia, berdasarkan kelompok usia yang diteliti dan perlakuan yang diberikan, dari $1 \%$ menjadi $29 \%$ pada orang lanjut usia yang tinggal dalam panti jompo, $14 \%$ menjadi $33 \%$ dalam perawatan jangka panjang di rumah, dan $10 \%$ pada populasi perawatan rumah sakit (17).

Massa otot menurun sebesar 1-2\% per tahun pada dekade ke-5 kehidupan. Kekuatan otot mulai berkurang pada dekadae ke-3 atau ke-4 dan menurun sebanyak $1,5 \%$ per tahun. Dekade ke -6 dan seterusnya menurun sebanyak 3\% per tahun. Akibatnya, kekuatan 
otot di dalam lansia harus dikurangi $20-50 \%$ (18).

Jumlah dan ukuran otot tetap relatif stabil dari masa pubertas hingga pada masa dekade ke-5 kehidupan, tetapi sejak saat itu massa otot mulai menurun drastis. Jumlah unit motor menurun, dan kekuatan otot berkurang (2).

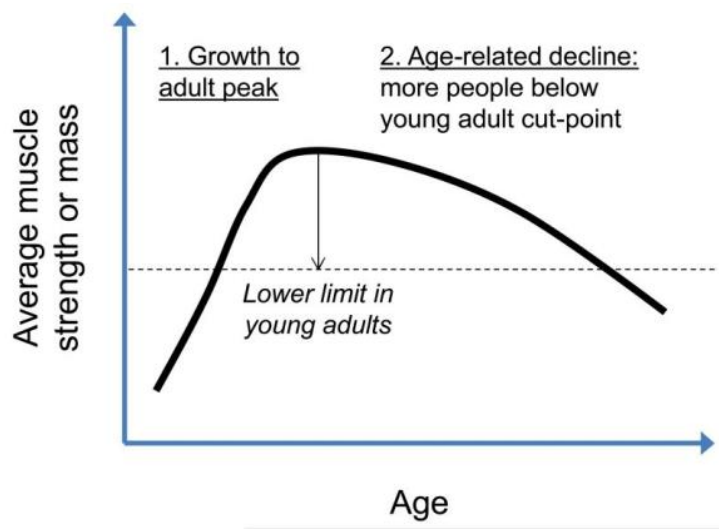

Gambar 2. Pendekatan Usia pada Sarcopenia (Sumber: Dodds, 2015).

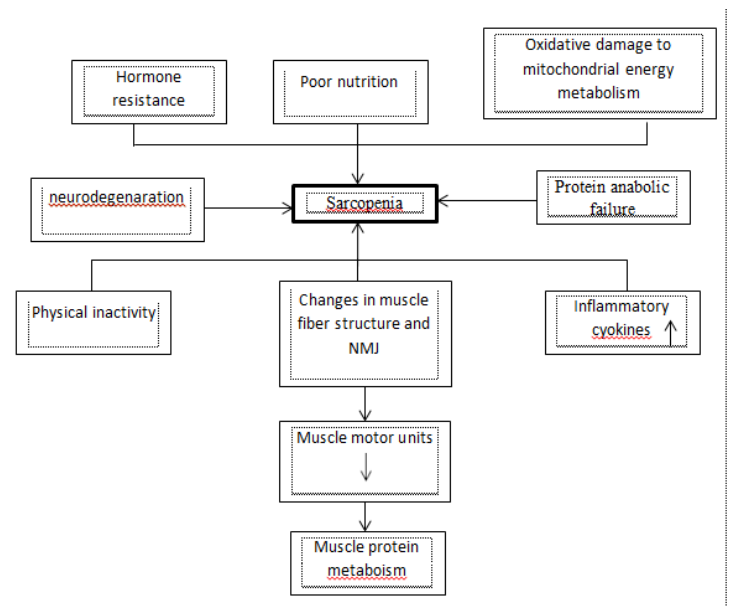

Gambar 3. Pathways Sarcopenia (Sumber: Woo, 2017).

\section{Jatuh pada Lansia}

Risiko mengalami cedera akibat jatuh tergantung pada kerentanan masing-masing pasien dan bahaya lingkungan yang terdapat disekitarnya. Frekuensi jatuh pada seseorang terkait dengan efek akumulasi berbagai gangguan yang terjadi karena adanya perubahan usia (19).
Jatuh adalah salah satu masalah kesehatan yang sering terjadi pada lansia 65 tahun ke atas (20). Di beberapa Negara didapatkan data, 28-35\% lansia orang berusia 65 tahun ke atas atau lansia yang berusia 70 tahun mengalami kejadian jatuh sekitar 32$42 \%$ setiap tahun, dan $40 \%$ dari orang-orang tersebut dilaporkan mengalami kejadian jatuh yang berulang (21).

Faktor risiko terkait dengan kejadian jatuh dibagi menjadi faktor intrinsik dan ekstrinsik, dan kombinasinya. Faktor intrinsik berupa faktor internal, seperti usia dan penurunan fungsi organ indera seperti penurunan ketajaman visual dan pendengaran, dan faktor ekstrinsik berupa lingkungan dan kondisi kehidupan yang mungkin mempengaruhi terjadinya jatuh (22).

Jatuh adalah penyebab utama cedera yang tidak begitu fatal dan bisa menyebabkan kematian pada orang dewasa yang lebih tua. Pencegahan kejadian jatuh/pengurangan risiko menjadi fokus utama dari berbagai masalah kesehatan. Selama 2 dekade terakhir, penelitian klinis telah memberi para dokter berbagai alat skrining untuk mengukur faktor risiko kejadian jatuh. Mayoritas dari langkahlangkah ini fokus pada satu domain intraindividual (misalnya, keseimbangan tubuh, kekuatan otot, fungsi penglihatan) atau ekstraindividual (misalnya, keamanan rumah) dari terjadinya risiko jatuh (23).

Sebanyak sepertiga dari lansia akan mengalami kejadian jatuh setidaknya sekali selama setahun. Kondisi sekunder dari kejadian jatuh sebenarnya dapat meningkatkan risiko dari cedera akibat jatuh (misalnya, patah tulang pinggul dan cedera kepala). Program pengurangan risiko jatuh meningkat secara signifikan dalam kesehatan masyarakat. Hal tersebut terjadi untuk mengidentifikasi para lansia yang membutuhkan intervensi untuk mengurangi risiko jatuh (24). 
Salah satu cara yang cukup efektif untuk menurunkan angka kejadian jatuh adalah dengan mempraktikkan gaya hidup sehat, menghindari stress, melakukan kegiatan latihan fisik (misalnya, berjalan, latihan kekuatan, atau aktivitas fisik yang dapat disesuaikan sendiri). Manfaat latihan fisik dalam meningkatkan kapasitas fungsional organ tubuh pada lansia yang sudah lemah. Program latihan yang disesuaikan dengan populasi ini telah terbukti efektif (25).

\section{SIMPULAN}

Sarkopenia yang dikenal dengan banyak orang merupakan proses terjadinya penurunan massa otot. Sarcopenia yang diperparah dengan adanya penurunan aktivitas fisik, dapat menyebabkan penurunan fungsi organ tubuh secara keseluruhan yang dapat mengakibatkan terjadinya kejadian jatuh pada lansia.

\section{UCAPAN TERIMA KASIH}

Penulis berterima kasih terhadap bantuan dari akademisi yang telah menulis kutipan atas artikelnya dalam persiapan ulasan ini. Penulis juga berterima kasih kepada editor/penerbit untuk setiap artikel dan jurnal itulah yang menjadi sumber literatur itu telah dibahas dan ditinjau dalam hal ini artikel.

\section{KONFLIK KEPENTINGAN}

Penulis tidak memiliki konflik kepentingan, dan tidak ada afiliasi atau koneksi dengan atau dengan entitas atau organisasi apa pun, yang dapat menimbulkan pertanyaan bias dalam diskusi dan kesimpulan naskah.

\section{REFERENSI}

1. Cruz-Jentoft AJ, Pierre Baeyens J, Bauer JM, Boirie Y, Cederholm T, Landi F, et al. Sarcopenia: European consensus on definition and diagnosis Report of the European Working Group on Sarcopenia in
Older People. Age Ageing.
2010;39:412-23.

2. Dhillon RJS, Hasni S. Pathogenesis and Management of Sarcopenia. Clin Geriatr Med. 2017 Feb;33(1):17-26.

3. Cruz-Jentoft AJ, Sayer AA. Sarcopenia. Vol. 393, The Lancet. Lancet Publishing Group; 2019. p. 2636-46.

4. Hua H, Xu X, Tang Y, Ren Z, Xu Q, Chen L. Effect of sarcopenia on clinical outcomes following digestive carcinoma surgery: a metaanalysis. Vol. 27, Supportive Care in Cancer. Springer Verlag; 2019. p. 2385-94.

5. Berková M, Berka Z. Pády: významná pŕíčina morbidity a mortality seniorů. Vnitr Lek. 2018 Dec;64(11):1076-83.

6. Guirguis-Blake JM, Michael YL, Perdue LA, Coppola EL, Beil TL. Interventions to prevent falls in older adults: Updated evidence report and systematic review for the US Preventive Services Task Force. JAMA - J Am Med Assoc. 2018 Apr;319(16):1705-16.

7. Cruz-Jentoft AJ, Landi F, Schneider SM, Zúñiga C, Arai H, Boirie Y, et al. Prevalence of and interventions for sarcopenia in ageing adults: A systematic review. Report of the International Sarcopenia Initiative (EWGSOP and IWGS). Age Ageing. 2014 Nov;43(6):48-759.

8. Gschwind YJ, Kressig RW, Lacroix A, Muehlbauer T, Pfenninger B, Granacher U. A best practice fall prevention exercise program to improve balance, strength / power, and psychosocial health in older adults: study protocol for a randomized controlled trial. BMC 
Geriatr. 2013 Oct;13:105.

9. Domingues-Faria C, Vasson M-P, Goncalves-Mendes N, Boirie Y, Walrand S. Skeletal muscle regeneration and impact of aging and nutrition. Ageing Res Rev. 2016;26:22-36.

10. Kim H, Hirano H, Edahiro A, Ohara Y, Watanabe Y, Kojima N, et al. Sarcopenia: Prevalence and associated factors based on different suggested definitions in communitydwelling older adults. Vol. 16, Geriatrics and Gerontology International. Blackwell Publishing; 2016. p. 110-22.

11. Vieira LS, Gomes AP, Bierhals IO, Farías-Antúnez S, Ribeiro CG, Miranda VIA, et al. Falls among older adults in the South of Brazil: Prevalence and determinants. Rev Saude Publica. 2018;52.

12. Prevention of falls and fall-related injuries in community-dwelling seniors: an evidence-based analysis PubMed.

13. Maryam RS. Pengaruh Latihan Keseimbangan Fisik Terhadap Keseimbangan Tubuh Lansia Di Panti Sosial Tresna Werdha Wilayah Pemda Dki Jakarta , 2009. 2009;

14. Dewi AANTN. Perbedaan Aquatic Exercise Therapy dan Senam Aerobic Low Impact dalam Meningkatkan Keseimbangan Dinamis Pada Lansia di Banjar Dharma Santi Denpasar. Universitas Udayana, Bali; 2015.

15. Marzetti E, Calvani R, Tosato $M$, Cesari M, Di Bari M, Cherubini A, et al. Sarcopenia: an overview. Aging Clin Exp Res. 2017 Feb;29(1):11-7.

16. Laviano A, Gori C, Rianda S. Sarcopenia and nutrition. In:
Advances in Food and Nutrition Research. Academic Press Inc.; 2014. p. 101-36.

17. Woo J. Sarcopenia. Vol. 33, Clinics in Geriatric Medicine. W.B. Saunders; 2017. p. 305-14.

18. Yakabe M, Hosoi T, Akishita M, Ogawa S. Updated concept of sarcopenia based on muscle-bone relationship. Vol. 38, Journal of Bone and Mineral Metabolism. Springer; 2020. p. 7-13.

19. Fuller GF. Falls in the elderly. Vol. 61, American Family Physician. Am Fam Physician; 2000. p. 2159-68.

20. Delle Fave A, Bassi M, Boccaletti ES, Roncaglione C, Bernardelli G, Mari D. Promoting well-being in old age: The psychological benefits of two training programs of adapted physical activity. Front Psychol. 2018 May;9(MAY).

21. Boehm J, Franklin RC, King JC. Falls in rural and remote community dwelling older adults: A review of the literature. Aust J Rural Health. 2014;22(4):146-55.

22. Yoo JS, Kim CG, Yim JE, Jeon MY. Factors influencing falls in the frail elderly individuals in urban and rural areas. Aging Clin Exp Res. 2016 Aug;28(4):687-97.

23. Renfro MO, Fehrer S. Multifactorial screening for fall risk in communitydwelling older adults in the primary care office: Development of the Fall Risk Assessment \& Screening Tool. J Geriatr Phys Ther. 2011 Oct;34(4):174-83.

24. Lusardi MM, Fritz S, Middleton A, Allison L, Wingood M, Phillips E, et al. Determining Risk of falls in community dwelling older adults: A systematic review and meta-analysis 
using posttest probability. Vol. 40,

Journal of Geriatric Physical

Therapy. Lippincott Williams and Wilkins; 2017. p. 1-36.

25. Cadore EL, Rodríguez-Mañas L, Sinclair A, Izquierdo M. Effects of different exercise interventions on risk of falls, gait ability, and balance in physically frail older adults: A systematic review. Vol. 16, Rejuvenation Research. Mary Ann Liebert, Inc.; 2013. p. 105-14. 